\title{
Between life and death: exploring the sociocultural context of antenatal mental distress in rural Ethiopia
}

\author{
Charlotte Hanlon • Rob Whitley • \\ Dawit Wondimagegn • Atalay Alem • Martin Prince
}

Received: 15 July 2009 /Accepted: 13 January 2010 /Published online: 11 February 2010

(C) The Author(s) 2010. This article is published with open access at Springerlink.com

\begin{abstract}
The high prevalence of antenatal common mental disorders in sub-Saharan Africa compared to high-income countries is poorly understood. This qualitative study explored the sociocultural context of antenatal mental distress in a rural Ethiopian community. Five focus group discussions and 25 in-depth interviews were conducted with purposively sampled community stakeholders. Inductive analysis was used to develop final themes. Worry about forthcoming delivery and fears for the woman's survival were prominent concerns of all participants, but only rarely perceived to be pathological in intensity. Sociocultural practices such as continuing physical labour, dietary restriction, prayer and rituals to protect against supernatural attack were geared towards safe delivery and managing vulnerability. Despite strong cultural norms to celebrate pregnancy, participants emphasised that many pregnancies were unwanted and an additional burden on top of preexisting economic and marital difficulties. Short birth interval and pregnancy out of wedlock were both seen as shameful and potent sources of mental distress. The notion that pregnancy in traditional societies is uniformly a time of joy and happiness is misplaced. Although antenatal mental
\end{abstract}

C. Hanlon $(\varangle) \cdot$ D. Wondimagegn $\cdot$ A. Alem

Department of Psychiatry, Faculty of Medicine,

Addis Ababa University,

Addis Ababa, Ethiopia

e-mail: charlotte.hanlon@kcl.ac.uk

R. Whitley

Department of Psychiatry, Dartmouth Medical School,

Hanover, NH, USA

\section{Prince}

King's College London (Institute of Psychiatry), Department of Health Services and Population Research, London, UK distress may be self-limiting for many women, in those with enduring life difficulties, including poverty and abusive relationships, poor maternal mental health may persist.

Keywords Mental health · Ethiopia · Sub-Saharan Africa . Pregnancy · Qualitative

\section{Introduction}

Antenatal common mental disorders (CMD; significant levels of depressive, anxiety and/or somatic symptoms) are increasingly recognised to be of public health importance in low- and middle-income (LAMI) country settings (Patel et al. 2006; Rahman et al. 2007; Hanlon et al. 2009a). In sub-Saharan Africa (SSA), prevalence estimates for antenatal CMD are high, ranging from $19.0 \%$ to $41.0 \%$ using self-report symptom scales (Assael et al. 1972; Aderibigbe et al. 1993; Nhiwatiwa et al. 1998; Adewuya et al. 2006a; Collin et al. 2006; Rochat et al. 2006; Bernatsky et al. 2007) and from $8.9 \%$ to $16.7 \%$ using diagnostic interviews (Cox 1979b; Abiodun et al. 1993; Aderibigbe et al. 1993; Kaaya et al. 2002; Adewuya et al. 2007). This compares to lower prevalence estimates from recent meta-analyses of antenatal depression in highincome countries: $12.0 \%$ for self-report scales (Bennett et al. 2004) and $8.5 \%$ for clinical interviews (Gavin et al. 2005). Cross-cultural studies are few and far between, but also indicate higher antenatal CMD in SSA compared to high-income countries (Cox 1979b). Controlled studies from SSA have found the prevalence of CMD to be higher in pregnant compared to non-perinatal women (Cox 1979b; Fatoye et al. 2004; Adewuya et al. 2006a), suggesting that pregnancy itself is a risk factor for poorer mental health. 
Such findings led Cox to comment "the Rousseauesque belief that Africans have a trouble-free, 'natural' pregnancy is not substantiated" (Cox 1979b).

Suggested reasons for the elevated mental ill health associated with pregnancy in SSA include the societal pressures upon women to successfully bear children (Abiodun et al. 1993; Aderibigbe et al. 1993), traditional beliefs holding women responsible for puerperal ill health and poor perinatal outcomes (Cox 1979a) and the reality of the dangers associated with childbirth in settings of high maternal morbidity and mortality (Cox 1979b, 1983; Aderibigbe et al. 1993). There are no studies from SSA to have systematically explored given reasons for poor antenatal mental health using qualitative methods. Seeking to address this gap, we present findings from a qualitative study exploring the sociocultural context of women's antenatal mental ill health in Ethiopia.

\section{Methods}

The design was a qualitative study. Data were collected from September to November 2004. Ethical approval was obtained from the research ethics committees of the Ethiopian Science and Technology Agency and the Institute of Psychiatry, King's College London.

\section{Study setting}

The study was conducted in and around the demographic surveillance site (DSS) at the Butajira Rural Health Programme (BRHP), Ethiopia (Berhane et al. 1999), located $130 \mathrm{~km}$ south of the capital city Addis Ababa. Since 1987, all households in a defined geographical area have been visited every 3 months in order to document births, deaths and migration and thus define the base population to support epidemiological study. The Butajira DSS is typical of a rural Ethiopian setting, with health indicators approximating those found in national surveys (CSA 2006). A governmental hospital, which opened in 2001, has expanded access to obstetric care, but few women choose to deliver in this setting in keeping with other rural Ethiopian areas. In Butajira, maternal mortality rates are estimated at 400-850/100,000 births (Berhane et al. 2000). Nationally, only an estimated $28 \%$ of women attend for antenatal care and fewer than $10 \%$ of women deliver in a health facility (CSA 2006).

\section{Sample}

We initially identified a key informant woman who had lived in the area all her life and worked for the BRHP for some years. She was able to make use of her good standing and diverse contacts in the various sub-districts to identify potential participants and to introduce us into the community. Purposive sample was undertaken to identify community stakeholders with diverse perspectives on the experiences of women during pregnancy, childbirth and the postnatal period. We also used the sampling technique of snowballing, asking participants whether they knew of a woman who had experienced problematic perinatal mental distress.

In-depth interviews were conducted with pregnant $(n=$ 2 ) and postnatal $(n=4)$ women, a community leader, an Ethiopian Orthodox Christian priest, a Muslim traditional healer (kalicha), leaders of women's religious groups (Christian and Muslim; $n=3$ ), the gender officer from a local women's advocacy organisation, the head of Women's Affairs in the local government, two members of a women's microfinance organisation, a trained and untrained traditional birth attendant, a midwife, a community health agent, two BRHP workers and three women identified through the snowballing process as having perinatal distress states $(n=3)$. Five focus group disocussions (FGDs) were conducted with the following groups: (1) postnatal women, (2) pregnant women, (3) traditional birth attendants (TBAs) with experience ranging from 2 to 30 years, (4) grandmothers and (5) fathers. All participants were required to give informed consent.

The sociodemographic characteristics of participants are summarised in Table 1.

\section{Protocol}

All in-depth interviews and FGDs were conducted in Amharic, the official language of Ethiopia. The in-depth interviews were all conducted by an Ethiopian midwife (AH) with previous experience in qualitative data collection. The FGDs followed recommended methodology (Krueger and Casey 2009). AH conducted two of the FGDs and assisted in the other three FGDs. The FGDs with pregnant and postnatal women were conducted by female Ethiopian doctors. The FGD of fathers was conducted by a male researcher with masters in public health, trained in qualitative methods and familiar with researching in Butajira. The reason for using different facilitators for the FGDs was partly pragmatic, as two moderators were required per group, and partly in an attempt to encourage more active participation, i.e. choosing a male facilitator for the FGD with fathers.

Interviews and FGDs were tape-recorded, with a notetaker present dring the FGDs to document non-verbal communication. Recordings were transcribed in Amharic and translated into English prior to coding. Interviews and FGDs were conducted in a range of settings, including primary health care facilities, the project office, 
Table 1 Characteristics of participants for in-depth interviews and focus group discussions (FGDs)

\begin{tabular}{|c|c|c|c|c|c|c|}
\hline & In-depth interviews & $\begin{array}{l}\text { FGD } 1 \\
\text { Postnatal women }\end{array}$ & $\begin{array}{l}\text { FGD } 2 \\
\text { TBAs }\end{array}$ & $\begin{array}{l}\text { FGD } 3 \\
\text { Grandmothers }\end{array}$ & $\begin{array}{l}\text { FGD } 4 \\
\text { Fathers }\end{array}$ & $\begin{array}{l}\text { FGD } 5 \\
\text { Pregnant women }\end{array}$ \\
\hline Number of participants & 25 & 11 & 11 & 10 & 10 & 11 \\
\hline Duration (h) & $0.75-2.00$ & 1.50 & 3.00 & 2.50 & 2.50 & 2.00 \\
\hline Age (years) & $21-70$ & $16-31$ & $20-60$ & $40-75$ & $21-39$ & $19-33$ \\
\hline Gender (female) & 19 & 11 & 11 & 10 & 0 & 11 \\
\hline \multicolumn{7}{|l|}{ Marital status } \\
\hline Single & 3 & - & 1 & - & - & - \\
\hline Monogamous & 13 & 7 & 9 & 3 & 10 & 8 \\
\hline Polygamous & 5 & 4 & - & 2 & 0 & 3 \\
\hline Separated & 2 & - & - & - & - & - \\
\hline Widowed & 2 & - & 1 & 5 & - & - \\
\hline \multicolumn{7}{|l|}{ Schooling } \\
\hline None & 12 & 10 & 8 & 9 & - & 6 \\
\hline Grade $1-9$ & 6 & 1 & 3 & 1 & 10 & 5 \\
\hline$\geq$ Grade 10 & 7 & - & - & - & - & - \\
\hline \multicolumn{7}{|l|}{ Religion } \\
\hline Muslim & 13 & 11 & 7 & 8 & 7 & 9 \\
\hline Orthodox & 10 & - & 3 & 2 & 2 & 2 \\
\hline Protestant & 2 & - & 1 & - & 1 & - \\
\hline \multicolumn{7}{|l|}{ Ethnicity } \\
\hline Meskan & 13 & - & 6 & 9 & 8 & 11 \\
\hline Mareko & 1 & - & 1 & - & - & - \\
\hline Silti & 2 & 11 & 1 & - & - & - \\
\hline Other & 9 & - & 3 & 1 & 2 & - \\
\hline
\end{tabular}

other office facilities or people's own homes. At all times, privacy was assured. Non-professional participants received remuneration for transport costs.

Topic guide

Interviews and FGDs were loosely structured around pregnancy, birth and the postnatal period. Open questions were used to enquire about the kinds of traditions and restrictions a pregnant woman might be subject to, the types of difficulties pregnant women can face and the sources of support they could expect to rely upon. Planned probes included direct questionning about previously identified common attributions for mental illness in Ethiopia (Alem et al. 1999), namely evil eye, bewitchment, ancestral troubles, spiritual problems and mental ('nervous') problems in the perinatal period, with follow-up questions aiming to elicit specific examples known to the participant. The interviewer took care to be sensitive to topics initiated by the participant and to allow the interview to proceed in as naturalistic a manner as possible. The topic guide developed iteratively as the study progressed.
Analysis

Initial analysis proceeded in tandem with data collection, with discussion of emerging themes between $\mathrm{CH}$ and $\mathrm{AH}$. To improve rigour of analysis, following completion of data collection, $\mathrm{CH}$ and DW independently coded four transcripts using descriptive codes. Coding schemes were compared and rationalised, with discussion about points of disagreement. $\mathrm{CH}$ and DW then applied these codes to two further transcripts as a cross-check. $\mathrm{CH}$ recoded the remaining transcripts, drawing upon additional codes where the data required. Prior to drafting the paper, the authors were aware of findings from a large population study of antenatal common mental disorders in Butajira investigating cross-sectionally associated variables and the impact on perinatal outcomes (Hanlon et al. 2008, 2009a). Computer software was used to facilitate data management (Muhr 1997). In accordance with the tenets of inductive analysis (Glaser and Strauss 1967), care was taken to allow codes to emerge from the data. Higher order themes were formed which were tested back against the data and discussed. Illustrative quotes were selected with agreement from all authors. 


\section{Results}

Although many participants were quick to affirm the cultural norm that a woman would be happy to discover that she was pregnant, almost all spoke about negative aspects of pregnancy that might threaten mental well-being: the vulnerability of the pregnant woman to physical and supernatural misfortune, pregnancy as an additional burden and, for some women, the shame of untimely pregnancy.

Natural and supernatural vulnerability

The precarious status of the pregnant woman, regardless of her living standard, was a preoccupation running throughout the interviews and discussions. Most eyes were fixed on the looming spectre of childbirth, with its attendant risks of pain, injury and death. However, the vulnerability of the pregnant woman to supernatural attack was also emphasised. The pre-eminent concern was for the woman's wellbeing, with only a minority of participants expressing worries about the unborn baby. When such worries were conveyed, it was more often in terms of the harm the foetus could bring to the woman.

But still, being pregnant makes you feel insecure. If

God helps me, I hope I will make it... I fear I will die.

That is my biggest worry. So, if God saves me, I will

have my baby in my arms and I will be saved. If not, I

will die. So I usually say I am between life and death.

IV03 Urban pregnant woman

The pregnant woman's destiny is seen to be in the hands of God or Allah, reflected in participants' emphasis upon the need for the pregnant woman to make supplication to God to grant a safe delivery. Prayer ceremonies were prescribed both for Christians and adherents to Islam. Other participants similarly spoke of pregnancy as a time for the woman to behave well, seek forgiveness from others, avoid conflict and fulfil her social obligations, all of which are activities undertaken by persons seen as near to death.

Almost all antenatal sociocultural practices identified by participants were directed at managing the pregnant woman's vulnerability, thus raising fears about what would happen if she did not adhere. For example, pregnant women were required to continue working until they delivered, as captured by the proverb quoted by many participants 'work is good for the pregnant woman, as it eases the pain for the labouring woman' (IV06 postnatal woman). Another strategy to facilitate delivery was also prominent in the discussion: restricting intake of water and sugar cane so that the baby might not be too big for delivery. This was widely endorsed with tales of women who had not followed the advice and gone on to have difficult labours.
In addition to fears about physical vulnerability in pregnancy, participants spoke of the heightened risk of supernatural attack. No participant spoke of any public celebration or recognition of the newly pregnant woman. On the contrary, most reported that pregnancy should be concealed until it could no longer be denied. For most participants, pregnant women were expected to avoid courting attention, to wear loose clothes and ensure that they covered up their pregnancy. Any woman flaunting her pregnancy, especially if she had previously had easy pregnancies, might become victim to evil eye or bring other types of misfortune upon herself.

... I had a friend who didn't cover her abdomen when she is pregnant and everybody said 'why didn't she do this?' and she got everyone's attention. When she delivered her baby died straight afterwards. Everybody said that this was the evil eye. They said that had she not behaved this way her baby might have been alright.

IV01 Butajira Rural Health Programme co-ordinator

Participants varied in their level of commitment to the prescribed practices. While some participants said that poor families were exempted from derema [prayer ceremony], non-performance was thought likely to exacerbate fears in those who placed their faith in the ceremony. Non-adherence to other traditional practices might also result in disapproval and blame in the event that something goes wrong.

For the majority of participants, worry and fear in pregnancy arising from perceived vulnerability were considered to be normal and expected phenomena, without any pathological significance.

It is normal to be worried during pregnancy, especially towards the end of the pregnancy. So we pray to God and the holy mother, Mary, to keep us safe. That is the only thing we will do...

IV12 Untrained TBA from Butajira town

She will always be worried about the time of delivery.... I think every pregnant woman might think about these things.

IV 13 Rural postnatal woman

Only one participant identified levels of worry that were considered to be abnormal and needing special intervention. This participant was a trained TBA and, in part, may have been emphasising to the interviewer (a midwife) her willingness to embrace biomedical concepts and refer to health facilities, given that TBAs have sometimes been criticised for their traditional beliefs and unwillingness to refer. Nonetheless, the TBA identified degrees of antenatal anxiety that she considered to be outside the norm.

Sometimes there is psychological problem. Women become nervous and worry too much. But when I face 
such kinds of problem with a woman, I immediately send them to the hospital.

AH: What kinds of symptoms do those women have?

$\mathrm{R}$ : The women I sent to the hospital get nervous and sometimes they would worry for no reason. Sometimes she thinks 'Will I get sick? Will I die?'. So if I feel her condition is not normal, I send this kind of women to the hospital.

IV09 Trained TBA from Butajira town

Pregnancy as a burden

For healthy women with enough to live on, for first-time mothers, for those who had waited a long time to conceive and for those with supportive husbands, pregnancy was assumed to bring happiness. Furthermore, participants recognised child-bearing as a woman's duty as well as her joy, helping to stop a husband taking another wife or casting her out of the house if she was unable to bear a child. However, participants cautioned that with increasingly difficult living conditions, pregnancy was often unwelcome and seen to magnify existing problems. For women without resources, there would be no possibility of rest from her usual workload and no nutritious food to sustain her. She would continue with her usual fight for survival, only additionally burdened by pregnancy.

If she doesn't have enough to care for her children or if she doesn't have anything to give them, becoming pregnant again is adding to that problem. In previous days, if you said 'I don't want to have any babies' this would be shameful, but now people want to have only two children.

IV12. Untrained traditional birth attendant

The bind for the woman was noted to be that she bears the responsibility for an unplanned pregnancy, but has little control over when she conceives, '...in order to stay in her home she has to deliver, but not too much' (IV19). Thus a number of participants spoke of pregnancy being unwanted when the woman already had too many children, leading to distress and unhappiness. Being stretched to the limits, pregnancy could become a catalyst for quarrelling within the household leading to further erosion of the care and support the pregnant woman might expect. Some participants spoke of their own experiences of loving and supportive husbands; however, many participants also spoke of how a bad marital relationship will worsen under the additional strains of pregnancy or how a good relationship may turn bad. The pregnant woman was described as being more demanding of her husband because of her additional needs. In households where these additional resources were unavailable, her requests would be a source of conflict and may exacerbate any tendencies for the husband to argue with her and beat her.
Usually when a woman becomes pregnant, the peace in her house will be disturbed.... Before pregnancy, they are in love and caring. Everything. But when the woman becomes pregnant, they start to argue.

IV09 Trained traditional birth attendant

The negative impact of a poor or deteriorating marital relationship upon the well-being of the pregnant woman was clearly articulated by the participants. Such experiences were held as a reason for a woman to regret her pregnancy. As the woman below points out, problems with her husband fuelled her feelings of vulnerability. Difficulties that may be endured at other times become overwhelming when pregnancy increases the woman's dependence on the very person she wishes to escape from.

I regret that I became pregnant.... I know he increased his abuse because he knows that I don't have anybody to protect me and he knows that I need support in this period.... It's me who suffers with the pregnancy [starts crying]. If I had not been pregnant, I would not have been vulnerable like this. It is this pregnancy that made me vulnerable to this suffering...he also knows this [cries].

IV28 Urban pregnant woman

\section{Shameful pregnancy}

Particular difficulties were said to face women who became pregnant outside of marriage or those who became pregnant when still within the postnatal period for their previous child. In the case of the latter, violation of the taboo on sexual relations in the postnatal period was at the heart of the issue. In both situations, shame was said to come upon the woman leading to the pregnancy becoming unwanted. A number of participants spoke of the extreme cases when women resorted to deliberate termination of pregnancy because of the ostracism.

If an unmarried girl gets pregnant she might become an outcast.... The family will accept the baby more than the woman. This can bring emotional problems upon the unmarried pregnant girls.

IV01 Butajira Rural Health Programme Co-ordinator

They will all talk about her. 'Did she become pregnant again?' 'Didn't she just deliver? When did she get pregnant?'... She will be worried. She won't even want to go to the 'Likso bet' [mourning ceremony].... So she will want to hide herself when she is pregnant. Or sometimes women will even want to get an abortion because of fear of this 'Yesawaff' [attracting attention and inviting misfortune].

IV13 Rural postnatal woman 
One participant spoke of the desperation of a woman who had conceived straight after her previous birth, even to the extent of threatening suicide.

I think she had sex during her postnatal period.... In the second month she came to me saying she wanted to go to the hospital. I asked her why and she told me that she was pregnant....Then I said 'How can I help you now?'

-'I want an abortion'

- 'That it not possible'

- 'Then I will strangle myself'

IV18 Women's Affairs Officer

\section{Discussion}

In this qualitative study from a predominantly rural area of Ethiopia, the realities of high maternal mortality, poor obstetric and family planning services, poverty and domestic violence conspired to threaten the mental well-being of pregnant women. Worry and fear were seen as commonplace, whether due to concerns about delivery, supernatural attack or failure to adequately adhere to prescribed sociocultural practices. Poverty and domestic violence rendered pregnancy burdensome and a source of regret to affected women. The lack of control over pregnancy timing was associated with shame and despair in unmarried, recently delivered and multiparous women, prompting many to seek illegal termination of pregnancy.

\section{Vulnerability and fear}

Our findings of pregnancy as a time of vulnerability and fear echo those from previous qualitative and anthropological studies of pregnant women from developing countries (Mead and Newton 1967). In Somali women who had migrated to Sweden, fear of dying and complicated delivery were prominent and associated with 'survival behaviours', such as voluntary food restriction to reduce the size of the fetus (Essen et al. 2000). In urban Indonesian women, exploration of emotional disturbance associated with pregnancy identified 'feeling anxious and worried', largely in relation to the forthcoming delivery, as predominant (Andajani-Sutkahjo et al. 2007). Rural pregnant women from the Kipsigis community in Kenya were reluctant to disclose pregnancy for fear of evil eye and tended to report negative dreams and memories during this period (Harkness 1987). Pregnant women in Mozambique were said to be preoccupied by their vulnerability to sorcery, witcheraft and other supernatural attack which might result in serious pregnancy and obstetric complications (Chapman 2004).
Fear in pregnancy: realistic or pathological?

Understandable fear of the complications of pregnancy and childbirth may partly explain the high prevalence of antenatal CMD in LAMI countries. Previous experience of obstetric complications or perinatal death was associated with antenatal CMD in most (Nhiwatiwa et al. 1998; Fatoye et al. 2004; Adewuya et al. 2006a), though not all (Aderibigbe and Gureje 1992), studies from SSA. The elevated CMD seen in pregnant compared to non-pregnant women in SSA is largely explained by high levels of anxiety symptoms (Cox 1979b; Fatoye et al. 2004). Furthermore, CMD symptoms are consistently higher in pregnancy than in the postnatal period, and most antenatal CMD remits following delivery (Cox 1983; Jinadu and Daramola 1990; Aderibigbe et al. 1993; Nhiwatiwa et al. 1998; Collin et al. 2006). In one study, all CMD symptoms were significantly lower in the postnatal period but the symptoms of 'worrying' almost disappeared once delivery had been safely negotiated (Jinadu and Daramola 1990).

The finding that clinical diagnoses of anxiety disorders as well as self-reported anxiety symptoms are increased in pregnant women in SSA countries indicates that fear and worry are crossing the threshold of clinical significance (Abiodun et al. 1993; Aderibigbe et al. 1993; Adewuya et al. 2006a). In our study, participants tended to normalise the experience of fear, with little evidence to support a pathological syndrome. Nonetheless, regardless of aetiology, antenatal anxiety and depressive symptoms have been associated with a range of adverse effects: obstetric and perinatal complications (Chung et al. 2001), poorer antenatal health behaviours (Bonari et al. 2004) and childhood behavioural problems (O'Connor et al. 2002) in highincome country studies; low birth weight (Patel et al. 2006; Rahman et al. 2007), prolonged labour and delayed initiation of breastfeeding (Hanlon et al. 2009a) in LAMI countries. A recent critique of such studies raised concern that labelling worry as a pathological entity will create yet another prohibition on women's behaviour in pregnancy, 'don't be anxious', bringing with it further opportunity to blame the woman if things go wrong (Oates 2002). In the sub-Saharan African setting, any intervention to ameliorate high levels of fear and worry will need to be mindful of the realities of reproduction with limited access to obstetric care. Improving perinatal care is likely to be an important component of interventions to tackle antenatal mental ill health. Preliminary evidence for the success of such an approach comes from the reduction in CMD symptoms seen in women randomised to participate in groups seeking to address problems of maternal and infant mortality (Prost et al. 2009, personal communication).

In Western settings, women who have previously experienced a stillbirth have been found to have elevated 
risk of developing post-traumatic stress disorder (PTSD) symptoms in the subsequent pregnancy (Turton et al. 2001). In sub-Saharan Africa, complicated deliveries have been associated with PTSD in the postnatal period (Adewuya et al. 2006b) but the impact on the woman's antenatal mental health in future pregnancies has not been explored. In our study, participants did not describe any antenatal symptom states indicative of traumatic stress.

\section{Pregnancy as a burden}

Our previous paper exploring postnatal CMD in the same Ethiopian sample also found that women with pre-existing difficulties might be at particular risk of perinatal mental ill health (Hanlon et al. 2009b). Studies from SSA have shown that in a high proportion of cases, postnatal CMD was preceded by antenatal CMD: $73.2 \%$ of cases in Nigeria (Aderibigbe et al. 1993), 81.5\% in Zimbabwe (Nhiwatiwa et al. 1998), although only $29 \%$ in Uganda (Cox 1983). A plausible hypothesis is that women with the identified preexisting problems will be at greatest risk of antenatal CMD persisting into the postnatal period, and beyond. In support of this, in a cross-sectional survey of women of reproductive age in Butajira, both domestic violence (Deyessa et al. 2009) and extreme poverty (Deyessa et al. 2008) were associated with depressive disorder. Similarly, antenatal CMD was associated with increased hunger, indebtedness and selfreported poor marital relationship in our quantitative study of Butajira women (Hanlon et al. 2008). Given the high reported prevalence of domestic violence in this Ethiopian setting (Garcia-Moreno et al. 2006) and worsening economic conditions, poor perinatal mental health might be expected to become an increasing public health problem.

Shame and pregnancy

Short birth intervals have been associated with poor perinatal outcomes (Conde-Agudelo et al. 2006), but do not appear to have been investigated as a potential threat to mental health. Shame was the dominant emotion associated with conception during the postnatal time of the preceding child. This is similar to the Gambia study where women who conceived while still breastfeeding would be gossiped about (Stokes et al. 2008). Similarly, in our study, women who conceived out of wedlock would be ostracised and subject to shame. Shamed women might be driven to consider illegal termination of pregnancy or even suicide, giving an indication of the profound impact of these unwanted pregnancies upon the woman's mental health. Other studies from SSA have found unmarried women to be at increased risk of antenatal CMD (Adewuya et al. 2006a; Bernatsky et al. 2007). Unwanted or unplanned pregnancy has been associated with antenatal CMD in a
South African study (Rochat et al. 2006), as well as in our study from Butajira, Ethiopia (Hanlon et al. 2008). Some interlinking of the themes of pregnancy burden and shameful pregnancy is likely to be important in this setting. For example, women who are relatively disempowered in their marital relationship might be expected to have less control over the occurrence of pregnancy as well as being more vulnerable to domestic violence.

Of note, participants did not mention HIV/AIDS as being a concern for pregnant women. The prevalence of HIV/AIDS in Butajira and other rural Ethiopian areas has been found to be relatively low (around $0.7 \%$ ) but antenatal HIV testing is available and routinely offered to pregnant women so that awareness of the issue is widespread and has the potential to raise anxieties (CSA 2006). Studies from other SSA countries have, however, reported conflicting results. In South Africa, pregnant women of known HIV status were no more likely to report depressive symptoms than those who were HIV positive (Collin et al. 2006); however, in Angola, HIV positive women had significantly higher symptoms of mental distress (Bernatsky et al. 2007).

\section{Limitations}

Caution should be exerted in generalising these findings to all Ethiopian women, particularly as the operation of the DSS within Butajira could have a bearing on the experience of respondents. That said, many of the pertinent issues identified from this study are commonplace across the country and might be expected to threaten antenatal mental health in predominantly rural areas.

\section{Conclusion}

Our findings indicate that the notion that pregnancy in traditional societies is uniformly a time of joy and happiness is misplaced. Although self-limiting for the majority of women, high levels of antenatal mental distress may yet warrant psychosocial intervention to minimise adverse obstetric outcomes. Broader interventions focusing on improving perinatal care may provide the most appropriate approach to improving mental health. In a sub-group of women with enduring difficulties, including poverty and abusive relationships, the perinatal period may be additionally burdensome and lead to persistent mental ill health.

Acknowledgements The authors gratefully acknowledge the participants for generously giving of their time, and for all assistance received from the staff of the Butajira Rural Health Programme. We especially appreciate Ms Aynalem Haile-Michael's skill in conducting the in-depth interviews. We are grateful to the Wellcome Trust for funding the study.

Disclosure of interests None. 
Contribution of authorship Charlotte Hanlon took the lead on designing the study, was intimately involved in data collection, lead on the analysis and produced the first draft of the manuscript.

Rob Whitley supervised the study design and the data collection process, contributed significantly to the analysis and production of the final manuscript.

Dawit Wondimagegn was involved in data analysis and contributed to the final manuscript.

Atalay Alem was involved in the study design, interpretation of findings and drafting of the final manuscript.

Martin Prince was involved in the study design, interpretation of findings and drafting of the final manuscript.

Funding The study was funded by a Wellcome Training Fellowship for Charlotte Hanlon (GR071643).

Open Access This article is distributed under the terms of the Creative Commons Attribution Noncommercial License which permits any noncommercial use, distribution, and reproduction in any medium, provided the original author(s) and source are credited.

\section{References}

Abiodun OA, Adetoro OO et al (1993) Psychiatric morbidity in a pregnant population in Nigeria. Gen Hosp Psychiatry 15(2):125128

Aderibigbe YA, Gureje O (1992) The validity of the 28-item General Health Questionnaire in a Nigerian antenatal clinic. Soc Psychiatry Psychiatr Epidemiol 27(6):280-283

Aderibigbe YA, Gureje O et al (1993) Postnatal emotional disorders in Nigerian women. A study of antecedents and associations. Br J Psychiatry 163:645-650

Adewuya AO, Ola BA et al (2006a) Anxiety disorders among Nigerian women in late pregnancy: a controlled study. Archives of Women's Mental Health 9(6):325-328

Adewuya AO, Ologun YA et al (2006b) Post-traumatic stress disorder after childbirth in Nigerian women: prevalence and risk factors. Br J Obstet Gynaecol 113:284-288

Adewuya AO, Ola BA et al (2007) Prevalence and correlates of depression in late pregnancy among Nigerian women. Depress Anxiety 24(1):15-21

Alem A, Jacobsson L et al (1999) How are mental disorders seen and where is help sought in a rural Ethiopian community? A key informant study in Butajira, Ethiopia. Acta Psychiatr Scand Suppl 397:40-47

Andajani-Sutkahjo S, Manderson L et al (2007) Complex emotions, complex problems: understanding the experiences of perinatal depression among new mothers in urban Indonesia. Cult Med Psychiatry 31:101-122

Assael MI, Namboze JM et al (1972) Psychiatric disturbances during pregnancy in a rural group of African women. Soc Sci Med 6 (3):387-395

Bennett HA, Einarson A et al (2004) Prevalence of depression during pregnancy: systematic review. Obstet Gynecol 103 (4):698-709

Berhane Y, Wall S et al (1999) Establishing an epidemiological field laboratory in rural areas-potentials for public health research and interventions. The Butajira Rural Health Programme 198799. Ethiop J Health Dev 13(special issue):1-47
Berhane Y, Andersson T et al (2000) Aims, options and outcomes in measuring maternal mortality in developing societies. Acta Obstet Gynecol Scand 79(11):968-972

Bernatsky S, Souza R et al (2007) Mental health in HIV-positive pregnant women: results from Angola. AIDS Care 19(5):674-676

Bonari L, Pinto N et al (2004) Perinatal risks of untreated depression during pregnancy. Can J Psychiatry 49(11):726-735

Chapman RR (2004) A nova vida: the commoditization of reproduction in Central Mozambique. Med Anthropol 23(3):229-261

Chung TK, Lau TK et al (2001) Antepartum depressive symptomatology is associated with adverse obstetric and neonatal outcomes. Psychosom Med 63(5):830-834

Collin SM, Chisegna MM et al (2006) Factors associated with postpartum physical and mental morbidity among women with known HIV status in Lusaka, Zambia. AIDS Care 18(7):812-820

Conde-Agudelo A, Rosas-Bermudez A et al (2006) Birth spacing and risk of adverse perinatal outcomes: a meta-analysis. JAMA 295:1809-1823

Cox JL (1979a) Amakiro: a ugandan puerperal psychosis? Soc Psychiatry 14:49-52

Cox JL (1979b) Psychiatric morbidity and pregnancy: a controlled study of 263 semi-rural Ugandan women. Br J Psychiatry 134:401-405

Cox JL (1983) Postnatal depression: a comparison of African and Scottish women. Soc Psychiatry 18(1):25-28

CSA (2006) Ethiopia demographic and health survey 2005. Central Statistical Authority (CSA) and ORC Macro. 2001. Addis Ababa, Ethiopia, and Calverton, Maryland, USA

Deyessa N, Berhane Y et al (2008) Depression among women in rural Ethiopia as related to socioeconomic factors: a community-based study on women in reproductive age groups. Scand J Soc Health 36:589-597

Deyessa N, Berhane Y et al (2009) Intimate partner violence and depression among women in rural Ethiopia: a cross-sectional study. Clinical Practice and Epidemiology in Mental Health 5:8. doi:10.1186/1745-0179-5-8

Essen B, Johnsdotter S et al (2000) Qualitative study of pregnancy and childbirth experiences in Somalian women resident in Sweden. BJOG: An International Journal of Obstetrics \& Gynaecology 107 (12):1507-1512

Fatoye FO, Adeyemi $\mathrm{AB}$ et al (2004) Emotional distress and its correlates among Nigerian women in late pregnancy. J Obstet Gynaecol 24(5):504-509

Garcia-Moreno C, Jansen HAFM et al (2006) Prevalence of intimate partner violence: findings from the WHO multi-country study on women's health and domestic violence. Lancet 368(9543):1260 1269

Gavin NI, Gaynes BN et al (2005) Perinatal depression: a systematic review of prevalence and incidence. Obstet Gynecol 106:10711083

Glaser BG, Strauss AL (1967) The discovery of grounded theory: strategies for qualitative research. Aldine, Chicago

Hanlon C, Medhin G et al (2008) Detecting perinatal common mental disorders in Ethiopia: validation of the self-reporting questionnaire and Edinburgh Postnatal Depression Scale. J Affect Disord 108:251-262

Hanlon C, Medhin G et al (2009a) Impact of antenatal common mental disorders upon perinatal outcomes in Ethiopia: The PMaMiE Population-Based Cohort Study. Tropical Med Int Health 14(2):156-166

Hanlon C, Whitley R et al (2009b) Postnatal mental distress in relation to the sociocultural practices of childbirth: an exploratory qualitative study from Ethiopia. Soc Sci Med 69:12111219

Harkness S (1987) The cultural mediation of depression. Medical Anthropology Quarterly 1:194-209, Harvard School of Public Health 
Jinadu MK, Daramola SM (1990) Emotional changes in pregnancy and early puerperium among the Yoruba women of Nigeria. Int $\mathrm{J}$ Soc Psychiatry 36(2):93-98

Kaaya SF, Fawzi MCS et al (2002) Validity of the Hopkins Symptom Checklist-25 amongst HIV-positive pregnant women in Tanzania. Acta Psychiatr Scand 106(1):9-19

Krueger RA, Casey MA (2009) Focus Groups: a practical guide for applied research. Sage, California

Mead M, Newton N (1967) Cultural patterning of perinatal behaviour. In: Richardson SA, Guttmacher AF (eds) Childbearing - its social and psychological aspects. Williams \& Wilkins, Baltimore, pp 142-244

Muhr T (1997) ATLAS.ti: The knowledge workbench: Visual qualitative data, analysis, management, model building: Short user's manual. Scientific Software Development, Berlin

Nhiwatiwa S, Patel V et al (1998) Predicting postnatal mental disorder with a screening questionnaire: a prospective cohort study from Zimbabwe. J Epidemiol Community Health 52(4):262-266

O'Connor TG, Heron J et al (2002) Antenatal anxiety predicts child behavioral/emotional problems independently of postnatal depression. J Am Acad Child Adolesc Psych 41(12):1470-1477
Oates MR (2002) Adverse effects of maternal antenatal anxiety on children: causal effect or developmental continuum? Br J Psychiatry 180:478-479

Patel V, Prince M et al (2006) Maternal psychological morbidity and low birth weight in India. Br J Psychiatry 188:284-285

Rahman A, Bunn J et al (2007) Association between antenatal depression and low birthweight in a developing country. Acta Psychiatr Scand 115(6):481-486

Rochat TJ, Richter LM et al (2006) Depression among pregnant rural South African women undergoing HIV testing. JAMA: Journal of the American Medical Association 295(12):13761378

Stokes E, Dumbaya I et al (2008) The right to remain silent: a qualitative study of the medical and social ramifications of pregnancy disclosure for Gambian women. BJOG: An International Journal of Obstetrics \& Gynaecology 115:1641-1647

Turton P, Hughes P et al (2001) Incidence, correlates and predictors of post-traumatic stress disorder in the pregnancy after stillbirth. British Journal of Psychiatry 178:556-560, Royal College of Psychiatrists, United Kingdom 